\title{
Research on Improvement Mechanism of Financial Management to Service Capability of Chinese Technological Small and Medium Enterprises
}

\author{
Yuan Zhang ${ }^{1, a}$, Ying Chen ${ }^{1, b}$ \\ ${ }^{1}$ Accounting School, Nanfang College of Sun Yat-sen University, Guangzhou, China
}

\begin{abstract}
Technological SMEs are committed to the commercialization of scientific and technological achievements, and conducive to meeting social needs, increasing employment and promoting technological progress. However, in the actual development process, there are problems such as weak financial management ability and low external service level restricted development of Chinese technological SMEs. This paper analyzes the mechanism and existing problems of the financial management of Chinese technological SEMs in improving their service ability, and explores ways to improve their financial management and service capability.
\end{abstract}

\section{INTRODUCTION}

Financial management is an indispensable part in the development of enterprises. In order to upgrade the quality of external services and achieve win-win social and economic benefits, enterprises need to implement financial management scientifically and reasonably, which is of the top priority.

\section{IMPROVEMENT MECHANISM OF FINANCIAL MANAGEMENT TO SERVICE CAPABILITY FOR TECHNOLOGY SMES}

\subsection{Financial Support}

Enterprises and financial management develop together and rely on each other. Financial management, the most basic type of management activity in enterprise management, is mainly on the economic relations and economic activities of the enterprise's internal production and operation. It organizes various economic activities and deals with related financial relations. The implementation of financial management in technologybased SMEs can enable leaders to clearly understand and grasp the capital flow of enterprises in order to strengthen financial management. In addition, a reasonable plan for the company's existing capital can effectively improve the efficiency of capital use and effectively avoid unnecessary waste of capital. After understanding the financial management situation, leaders can obtain information related to the actual status of funds, then improve the later application of funds in a more scientific and systematic way according to the actual situation, and make corresponding investment decisions through the financial accounting of the financial department, which can make the decision feasible and help companies obtain more benefits. Moreover, financial management can provide overall planning for the funds in all project and activities, and cut the waste of capital effectively.

\subsection{Cost Control}

The cost control of an enterprise directly affects the profit of the enterprise, and the financial management of the enterprise can ensure the good operation of the enterprise project on the premise of the enterprise's investment project to develop a minimum input program. This is because a sound financial management system allows the financial management department of an enterprise to comprehensively grasp all aspects of information. So in the cost control of the project, the financial department offers the best investment program to achieve the minimization of investment and maximization of returns through the accurate and comprehensive understanding of all aspects of information. Effective financial management can be well coordinated with the enterprise's management system to achieve the strengthening of internal control. Only when an enterprise is constrained by the internal control, its internal business can be regulated well. In addition, the strengthening of internal control can enhance the supervision of the enterprise and create a better environment for the development of SMEs.

\subsection{Managemnt Consult}

Financial management can enable managers to understand the actual business situation in a specific period of time,

e-mail: azhangy3@nfu.edu.cn, Corresponding author: e-mail bcheny@nfu.edu.cn 
in order to have a more in-depth grasp of the profitability and solvency of the enterprise, to distinguish the various factors that affect the development of enterprises effectively and have a in-depth understanding of the above factors. For example, after knowing the micro and macro factors that affect the financial situation of the enterprise, managers can improve the quality and level of enterprise development management from the perspective of internal factors and external factors through financial management. Enterprise managers can also analyze the financial management status of a particular stage in a timely and effective manner through financial management, and then perceive the possible loopholes in the financial management of a particular period, which can help them to understand the current situation of enterprise development. To discover the loopholes and problems in management in the shortest time and, we can take appropriate measures to avoid further deterioration, ensure the profitability and solvency of the enterprise, and improve the mode and level of enterprise management. In addition, by discovering the internal contradictions in enterprise management, managers can take corresponding measures to promote the healthy development of enterprise management, thereby improving efficiency of the industry and enhancing market competitiveness.

\subsection{Supervisory Management}

In a scientific enterprise management system, the supervisory function is indispensable. The supervision of financial management is the guarantee for the correct and smooth development of the enterprise. At the same time, the supervision is also a way to optimize the enterprise management system. Supervision of employees can make them work more efficiently, which can help them get higher salaries. In this way, it not only highlights the value of the employees but also strengthens the business atmosphere. In addition, supervision of the company's capital can help the company to have a clearer idea of where the money is flowing, so that when the company needs money for turnover or investment, it can quickly find the source. Lastly, the supervision of financial personnel can prevent internal disputes and standardize the financial system of an enterprise, as well as prevent the unjustified loss of funds. The importance of financial management in a company is also the reason why it is necessary to monitor it.

\section{PPRoblems of TeChNOLOGical SMEs}

\subsection{Seriously underfunded and difficult to finance}

The steady flow of capital is an important guarantee for the long-term development of an enterprise. However, the characteristics of high-tech SMEs determine that external financing is relatively difficult, and insufficient funds often impede their subsequent development. According to statistics, only about $8 \%$ of our country's technologybased SMEs with certain achievements can get support from bank loan. Due to lack of funds, many companies with high technology content and good development prospects have grown slowly or even led to bankruptcy.

The main reasons for SMEs' difficulty in obtaining financing come from the uncertainty of business operations and the inadequacy of internal financial management mechanisms. Firstly, the operation of these enterprises is uncertain. The technology and products developed by technology-based SMEs are advanced and complex, and the success of which is influenced by many uncertain factors, which may lead to greater business risks; Second, technology-based SMEs often have only technology, patents, or even only creative conceptual models, with many intangible assets and few tangible assets, intangible assets that are difficult to value, and tangible assets that are insufficient as collateral for loans. Thirdly, some enterprises have unsound management system, with irregular management style, and lack of transparency in financial information; moreover, the financial institutions are not familiar with the credit status of enterprises. All the above factors undoubtedly increase the difficulty of financing for technology-based SMEs.

On the one hand, the above factors make financial institutions with the purpose of profit and prudent operation as the principle reluctant to lend to small and medium-sized technological enterprises for the sake of fund safety. However, on the other hand, the risks and opportunities of technological innovation activities coexist. Although the risks are high, once they succeed, the benefits are also high. Therefore, the cooperation between financial institutions and technological SMEs is not without benefits. It is reasonable and has a complete risk avoidance mechanism. Compared with the allocation of funds to traditional industries and traditional enterprises, a higher rate of return can be obtained. So, technology-based small and medium-sized enterprises have a strong desire for funds, and the financial institutions want to find new profit growth points. Therefore, there will be a convergence between them.

\subsection{Lack of technological innovation}

Compared with large domestic enterprises, the technology level of our science and technology-based SMEs, not to mention compared with foreign countries, is also very low. Take the labor equipment rate of industrial enterprises as an example, according to relevant information, the per capita fixed assets (original value) of China's independent accounting of large, medium and small industrial enterprises were 102,900 yuan, 51,100 yuan and 24,800 yuan, the per capita equipment level of small enterprises is 50 of the level of SMEs, $25 \%$ of large enterprises. In recent years, China's annual scientific and technological achievements are over 10000 , but only 20 of them turned into productivity, of which less than $5 \%$ of the industrial scale. The main factors hinder the technological innovation of SMEs, mainly are the lack of information, necessary science and technology loans and venture capital, as well as the incompetency of managers. According to statistics, there are 22 provinces and municipalities has established science and technology 
trust companies, venture capital companies, credit societies, etc., which amounting to more than 80 . The investment capacity of them reached 3.5 billion yuan, but rarely for medium-term venture capital.

\subsection{Disconnect between scientific research and financial accounting management}

As we all know, the core competitiveness of high-tech SMEs is core independent intellectual property rights, which mainly come from the scientific research activities of enterprises. From investigation, we found that in the management process of many technology-based SMEs, due to the failure in implementation of the management system of the enterprise, the financial department of the enterprise is not involved in the entire process of scientific research project management. Failing to participate in supervision, scientific research and financial management are disjointed, causing the latter to be unable to effectively manage and account for the technology and knowledge resources that the company depends on, thus unable to provide decision-makers with complete, true and effective finance information.

\section{Suggestions}

Difficulties in financing are the bottleneck in the development of most technology-based SMEs. Most technology-based SMEs cannot reach the threshold of bank credit due to lack of sound financial systems, financial statements, real data, and insufficient effective collateral, making it difficult for the bank to offer credit support. Therefore, for those SMEs, it is necessary to find more methods to improve its financial management capabilities, optimize the credit systems, continuously strengthen the financial management, and improve external service.

\subsection{Strengthen the management of corporate financial}

First, the technological SMEs should establish a series of sound and scientific system of financial forecasting, planning and control methods; make scientific projections and calculations of financial activities and financial results in the future; attach importance to the financial budget of the enterprise; allot and implement the targets determined by financial decisions to each department; and play a limiting and guiding role in financial activities.

Secondly, the technological SMEs should improve the financial control of enterprises, bring in advanced management methods from other countries, and establish a sound accounting control system. However, the introduction of methods can't be copied wholesale, but should be combined with their own situation to innovate and transform, and assimilate the essence and reject the dross. Use relevant information and specific methods to exert positive influence on various factors and conditions that affect the financial activities of the enterprise, so that they can be executed in accordance with the financial budget and accomplish the financial goals, and finish the daily work, strictly abide by the accounting system formulated by the state, establish accounts in accordance with the requirements of the relevant departments, record correctly, ensure the truthfulness, reliability and objectivity of accounting information, prepare annual financial statements in accordance with the requirements of the financial situation of the enterprise, pay taxes in a timely manner, do not evade taxes, pay debts in a timely manner, and do not maliciously default.

Thirdly, a sound scientific financial analysis and evaluation system should be established to improve the financial analysis ability of enterprises and use specific methods to analyze and evaluate financial work, and to summarize experience for future financial work of enterprises.

\subsection{Increase the involvement of finance departments in research management}

Under the current social and economic conditions, intellectual assets such as patents and technologies play an increasingly prominent role in all the assets of enterprises. A major source of intellectual assets is the scientific research of enterprises. Therefore, the investment of scientific research occupies a large proportion in many small and medium-sized technological enterprises and the importance of scientific research project management to technology-based SMEs is self-evident. Technologybased SMEs should formulate and improve the financial management system related to scientific research, so that the financial department will participate in the whole process from the project budget when the scientific research project is established, to the approval of the expenditure during the project execution, and then to the final account of the expenditure during the project acceptance. Only in this way can financial departments give full play to the functions of financial supervision and financial analysis, and continuously renew the target of corporate financial management.

\subsection{Establish a scientific organization management system}

In the process of financial management of technologybased SMEs, the determination of financial management targets and the expansion of financial management objects are the two major challenges faced by enterprises at present. Enterprises should improve the personnel's understanding of financial management, clarify the significance of financial management to promote enterprise development, build a scientific financial management system, and optimize the corporate governance structure. In addition, when establishing the management system for their own enterprise development, they need to actively change the original management style, such as the original passive bookkeeping, accounting and reporting to active participation in forecasting, control and decision-making, so as to further improve the internal control system of the enterprise. Enterprises should establish and improve incentive mechanisms to strengthen the sense of identity and 
belonging as well as risk values of employees, and achieve standardized management; develop and establish unique financial management methods according to the development status of the enterprise, so as to unify the rights, responsibilities and benefits of financial personnel.

\subsection{Improve credit guarantee system for SMEs}

First of all, technology-based SMEs should strengthen their credit construction. For enterprises with high credit, it is conducive to the healthy development between enterprises and banks and can reduce the cost of corporate financing. As far as it seems, the emergence of undesirable phenomena such as evasion of bank debts and tax evasion by technology-based SMEs has seriously damaged the quality and credibility of the enterprises themselves. Technology-based SMEs should strengthen the transparency of financial information, so as to enhance the trust of banks in the management level and sustainable development of enterprises, and improve the financing ability of technology-based SMEs themselves. Secondly, the government should provide guarantee for financing and expand financing channels of science and technologybased SMEs through the guarantee platform with the support of relative policies. Meanwhile, financial institutions should actively build a financial credit system for science and technology-based SMEs and conduct credit evaluation of science and technology-based SMEs effectively, which not only helps to reduce bank credit risks but also helps to guide the investment of credit funds correctly.

\subsection{Explore new financing models actively}

First of all, in order to solve the urgent problem of insufficient funds, on the one hand, we should encourage science and technology-based SMEs to use the pledge financing policy to use their patents or intellectual property rights for pledge financing, promote the transformation of enterprise patent achievements and the production and operation activities as well as technological upgrading of enterprises. On the other hand, we should encourage science and technology-based SMEs to issue private placement bonds. Compared with bank loans, due to the low threshold of the issuing body, bonds for small and medium-sized private enterprises have less restrictions on investors and more relaxed regulations on ratings and audits, so they are bound to gain the favor of SME financing. Second, we should introduce venture capital funds actively. Venture capital funds do not require the collateral guarantee of enterprise assets, and the procedures are relatively simple, which can effectively help the development and growth of science and technology-based SMEs in the start-up and growth period. In addition, technology-based SMEs that meet the requirements can also apply for the Technology Innovation Fund, which is a special government fund to support technology innovation in technology-based SMEs.

\section{REFERENCES}

1. Daisuke Tsuruta, "SME policies as a barrier to growth of SMEs" ,Small Business Economics, vol.54, no. 4, pp. 1067-1106, April 2020, doi: 10.1007/s11187-018-0119-0.

2. Hongyu Li, Junjie Wu, Zhiqiang Lu, "Bank diversity and SME innovation: evidence from China" Int. J. Bank Marketing, vol.38, no. 2, pp. 265-282,2020, doi: 10.1108/IJBM-06-2019-0216.

3. J. Dvorsky, J. Belas, B. Gavurova, and T. Brabenec, "Business risk management in the context of small and medium-sized enterprises," Economic ResearchEkonomska Istrazivanja, doi: 10.1080/1331677x.2020.1844588.

4. W. R. Lam and Y. Liu, "Tackling Small and Medium-Sized Enterprises (SMEs) Financing in China," Annals of Economics and Finance, vol. 21, no. 1, pp. 209-239, May 2020. [Online]. Available: $<$ Go to ISI $>$ ://WOS:000531067000010.

5. M. Z. Hoque, "Mental budgeting and the financial management of small and medium entrepreneurs," Cogent Economics \& Finance, vol. 5, no. 1, Feb 2017, Art no. 1291474, doi: 10.1080/23322039.2017.1291474..

6. T. Boshkov, "Creating Successful Management through Risk Exposure Detection and Access to Finance of the Company," Quality-Access to Success, vol. 18, no. 156, pp. 116-118, Feb 2017. [Online].

7. M. Chatterjee and T. Bhattacharjee, "Ownership concentration, innovation and firm performance: empirical study in Indian technology SME context," South Asian Journal of Business Studies, doi: 10.1108/sajbs-10-2019-0185.

8. Z. Geng, Z. B. Li, and J. Ma, "Research on the Relationship among Technology Sources, Learning Modes and Innovation Performance of Technical SMEs of Tianjin," (in English), Proceedings of the 2016 International Conference on Education, Management, Computer and Society, Proceedings Paper vol. 37, pp. 94-97, 2016. [Online]. Available: $<$ Go to ISI $>$ ://WOS:000388458100023.

9. H. Rachidi and M. El Mohajir, "Improving SMEs' performance using innovative knowledge and financial system designed from the Moroccan business environment," African Journal of Science Technology Innovation \& Development, doi: 10.1080/20421338.2020.1816264.

10. N. H. Wellalage and V. Fernandez, "Innovation and SME finance: Evidence from developing countries," International Review of Financial Analysis, vol. 66, Nov 2019, Art no. 101370, doi: 10.1016/j.irfa.2019.06.009. 